\title{
Strategic Innovation Planning and Partnerships: Aligning Market, Products/Services/Processes and Technologies
}

\author{
Mauro Caetano ${ }^{*}$, Daniel C. Amaral ${ }^{2}$ \\ ${ }^{1}$ Faculty of Business Administration, Accounting and Economy (FACE)/Agribusiness Post-Graduating Program (PPAGRO), \\ Federal University of Goias (UFG), Goiânia, Brazil \\ ${ }^{2}$ Sao Carlos School of Engineering (EESC), University of São Paulo (USP), São Carlos, Brazil \\ Email: *maurocaetano@face.ufg.br, amaral@sc.usp.br
}

Received September 11, 2012; revised October 17, 2012; accepted October 25, 2012

\begin{abstract}
There are different tools to support the innovation planning, however, the paradigm of open innovation shows that there is a need to adopt different partners in the development of technology, product, service or process, and many of the proposals in the literature ignore this theme on the innovation process. This study proposes a generic model to strategic innovation planning, especially for technology push approach. The model was developed from an action research and literature review, which includes these elements. It contains three different stages ranging from the identification of markets and possible partners to carry out a strategic plan for innovation. The application identifies the technology core of the organization and possible technology, products, services or processes to be developed. Results on the practical application of the model over different innovation processes can be objects of future research.
\end{abstract}

Keywords: Innovation Process; Open Innovation; Strategic Plan

\section{Introduction}

The importance of innovation for the organization competitiveness suggest than more and more researchers and managers focus their studies on the development of instruments, such as methods and tools, which contribute to making the innovation a reality. Many of these instruments also seek to include elements related to the open innovation paradigm, especially with regard to the planning of new technologies, products, services or processes according to the market opportunities.

Several instruments presented by literature can support the innovation planning at the organization, as the technology and product development process models [1-4], the fuzzy front end of innovation methods $[5,6]$, the technology roadmap methods [7-16] and others which contribute to identify market, product and technologies at the innovation planning.

One of the main tools supporting innovation and may be customized at the open innovation paradigm is the TRM. It can offer better results if the enterprise expands its search for innovation information and market opportunities to the external agents located in several parts of the world. This is due the fact that the increasing complexity of technologies embedded in new products depends on greater knowledge than ever and, consequently,

${ }^{*}$ Corresponding author. on the cooperation among different specialists. This makes the process of innovation more complex and their successful adoption more challenging. In fact, even mega-corporations, once famous for their self-sufficient $\mathrm{R} \& \mathrm{D}$ structures and product development processes, find it difficult to master satisfactorily all of their technologies due to the fast pace of today's scientific advancement. It appears that the practical application of open innovation can provide an adequate answer to this challenge because its main strategy is to deliberately develop new technologies through partnerships with diverse organizations instead of adhering to the classic model (closed innovation), which employs internal R\&D structures [17].

Despite the literature demonstrating the use of open innovation as a best practice innovation management, and there are several instruments that contribute to innovation planning, they neglect the adoption of partner at the technology, product, service and process development or market exploration. These different instruments presented do not provide a systematic solution to this action. Recently, studies as Caetano and Amaral [8], Lichtenthaler [18], Huizingh et al. [19] and Badawy [20], also demonstrates this problem.

In this sense, the main goal of this study is to answer how to consider the partnership adoption to align market, PSP (product, service or process) and technology on the 
strategic innovation planning at the open innovation paradigm and technology push approach. This study proposes a model to solve this question from different stages.

\section{Theoretical Bases}

In order to effectively integrate technology into PSP it is fundamental that organizations adequately plan their technologies $[21,22]$. Several tools may be employed to support this planning, e.g., generic management models [1-4] and specific methods and tools [5,6,8-12,15,16]. These are proposals which are applied through the use of information on both market and products and technologies.

Some of these tools were created from models for technology planning based on business process, identifying phases and activities, as in Clark and Wheelwright [1], Clausing [2], Cooper [3], Creveling et al. [4], Schulz et al. [23] and Whitney [24]. Besides, these models address technology development as a process, with well defined stages and decisions, which enables the identifycation of gaps leading to the establishment of partnerships.

An analysis of methods to support the innovation planning has been made on literature. Among them, one of the most cited has been the technology road mapping (TRM), and among the most cited TRM is the T-PLAN, developed by Phaal et al. [15]. The authors suggest looking for partners in order to acquire certain necessary resources. However, they do not specify how this search should be performed or take into account the different types of partners and the criteria needed for their selection and prioritization. Furthermore, from the state of the art on open innovation analysis, Huizingh [19] presents the challenge of integrating current management practices and issues of open innovation. The Table 1, presented by Caetano and Amaral [8], summarizes the studies related to innovation planning method and the adoption of partnerships identified on literature.

According to Table 1, the different methods present considerations about partnerships, but do not presents a systematic framework to adoption of partner during the innovation process. Despite Albright and Kappel [7] present the technologies which can be acquired from the partners, they do not classify the partners and the criteria to select it. This happened with another studies, e.g., on McAdam et al. [30], which addresses the use of partnerships in the development of new materials, the authors propose to systematize the incorporation of partnerships into technology planning from benchmarking, meetings with partners, and the use of a portal of knowledge to define the necessary expertise. However, the authors do not differentiate among types of partners or present predefined criteria for their selection and prioritization. This shows the limitation on considering partnerships adoption on innovation planning.

\section{Methodology}

This study began with a bibliographical review [31] and a specific action research [32,33]. An action-research team was form with members of a research group to which the authors belong and members of an organization which develops technologies and needs partners to develop PSP to explore markets, a common situation experienced by companies.

The first step of the study was to make a diagnosis of the management process of technology projects from this organization, identifying their characteristics and difficulties in integrating their technologies into PSP of commercial interest. The diagnosis also involved the analysis of distinct projects of technologies developed by this organization, which made possible to identify their main difficulties in the innovation process. Among these difficulties was the absence of more elaborated strategy to support the innovation process.

The second step was the creation of strategic plan to a technology which was in its final stages of development at this organization. Altogether, it took about one year of intervention and approximately 400 hours were spent in the action research. At the end of the intervention the field data, minutes of meetings, artifacts and templates for documents and records generated in minutes were synthesized on a guide for the planning application in the organization as described at Caetano and Amaral [8].

The third and final step was the analyses of this guide on different fields, as services and process development. It was possible to create a generic model expanded to strategic innovation planning at light of open innovation and technology development literature.

\section{Strategic Innovation Planning Considering the Partnerships and Open Innovation Paradigm}

The results from this research present a strategic innovation planning model with three different stages according to open innovation proposal. The model is based in central idea that the company should advise your effort of innovation from your core technology and ideas about possible technology, products, services or processes that can be developed. The company, a technology based enterprise or research lab, use its core technology to develop masters package technology which goes to the market through partner companies, which produces the finals products, services or process (PSP).

The partnerships with customers and other foreign technology developers can provide important information about the market and the related technologies. 
Table 1. Studies related to innovation planning and the adoption of partnerships.

\begin{tabular}{|c|c|c|}
\hline Authors & Description of application & Adoption of partnerships \\
\hline Albright and Kappel [7] & $\begin{array}{l}\text { Distributed in three sections: market, product, and technology; market } \\
\text { trends, competitors' strategies, competitive products, and technologies } \\
\text { needed for these products are identified. }\end{array}$ & $\begin{array}{l}\text { Indication of technologies which } \\
\text { can be acquired from the partners. }\end{array}$ \\
\hline Daim and Oliver [9] & $\begin{array}{l}\text { Method application in four steps: planning and identifying the needs of the } \\
\text { energy sector, training for the preparation of road mapping, implementation } \\
\text { by defining goals and monitoring the roadmap. }\end{array}$ & $\begin{array}{l}\text { Identifies organizations that } \\
\text { develop technologies in similar } \\
\text { areas. }\end{array}$ \\
\hline Gerdsri et al. [11] & $\begin{array}{l}\text { Application through the preparation of the organization, identification of } \\
\text { people to be involved and the necessary information, and integration of the } \\
\text { roadmap in planning business activities, being constantly revised. }\end{array}$ & $\begin{array}{l}\text { Involvement of key players in the } \\
\text { organization in innovation } \\
\text { planning. }\end{array}$ \\
\hline Holmes and Ferrill [12] & $\begin{array}{l}\text { Implementation of Operation and Technology Road Mapping (OTR) in five } \\
\text { modules: analysis of current technological situation and market position, } \\
\text { analysis of market requirements, conceptualization of products and } \\
\text { services, identification of technological solutions, and drawing of the } \\
\text { roadmap by integrating all these items. }\end{array}$ & Do not consider partnerships. \\
\hline Kim et al. [25] & Method to identify development areas in building in the Republic of Korea. & $\begin{array}{l}\text { There were partnerships among the } \\
\text { interviewed organizations for the } \\
\text { innovation planning. }\end{array}$ \\
\hline Lee et al. [26] & $\begin{array}{l}\text { Use of a QFD matrix to identify gaps in the relationship between data on the } \\
\text { needs of consumers that use a given technology and engineers that develop } \\
\text { it, pointing out key elements for new competitive technologies. }\end{array}$ & Do not consider partnerships. \\
\hline Lee et al. [6] & $\begin{array}{l}\text { Method divided into six stages: initiation, selection of topics to be } \\
\text { addressed, assessment of technology needs, preparation of technology } \\
\text { development plan, road mapping implementation, and roadmap updating. }\end{array}$ & $\begin{array}{l}\text { Seeks to identify consortium } \\
\text { opportunities between enterprises } \\
\text { and research institutes. }\end{array}$ \\
\hline Lee et al. [27] & $\begin{array}{c}\text { Application from analysis of patents to identify organizations that can } \\
\text { develop certain sub-technologies or products in the search for new business } \\
\text { opportunities. }\end{array}$ & $\begin{array}{l}\text { The analysis of patents indicates } \\
\text { organizations that could become } \\
\text { partners. }\end{array}$ \\
\hline Lichtenthaler [28] & $\begin{array}{l}\text { Method taking into accounts the possibilities of commercialization of } \\
\text { ready-developed technologies with external agents. }\end{array}$ & $\begin{array}{l}\text { Seeks commercial partners for } \\
\text { licensing. }\end{array}$ \\
\hline Mitchell and Nault [29] & $\begin{array}{c}\text { They indicate that cooperative planning can reduce both downstream as } \\
\text { upstream rework on a project. }\end{array}$ & Interdepartmental partnerships. \\
\hline Phaal et al. [15] & $\begin{array}{l}\text { Workshops with multidisciplinary teams from business and technical areas } \\
\text { to roadmap products and technologies needed for specific products and } \\
\text { markets. }\end{array}$ & $\begin{array}{l}\text { Adoption of partnerships to provide } \\
\text { certain resources. }\end{array}$ \\
\hline Wells et al. [26] & $\begin{array}{c}\text { Method applied in two workshops: planning to identify the participants' } \\
\text { interests through brainstorming techniques, relate identified opportunities, } \\
\text { and draw a roadmap. }\end{array}$ & $\begin{array}{l}\text { Suggests the participation in } \\
\text { networks to carry out research } \\
\text { activities. }\end{array}$ \\
\hline
\end{tabular}

According to Figure 1, which presents the proposal stages, the starting point of strategic innovation planning is an initial idea of the potential PSP (product, service or process) which can be developed considering the core technology at the organization. This initial idea refers to an initial perception about its power of create value to the consumer or enterprises, that has been mentally devised by the professionals from the organization, but has not been developed before.

Based on this initial idea of PSP to be developed, at the stage I must be created the starting term, which has some information like the project name, project manager and team members. The goal of this stage I is to identify and prioritize potential markets to be exploited with the initial idea of PSP.

The identification of potential markets is based on re- sults of a survey of potential group of consumers to the PSP idealized. It should provide data regarding the size of this market, in terms of volume of business generated during recent periods of time, and their expected future growth.

At the same time, future partners, known as market partners (MPs), are also identified for each market. When gathering information about market characteristics and sizes, the participants of the strategic innovation planning team also identify players that distribute or develop this kind of PSP and can be a partner to the organization in the introduction of these elements in the market. This provides the opportunity of building partnerships at the marketing exploring. Furthermore, it is possible to involve the partner at the innovation planning through the provision of market information and new possibilities. 


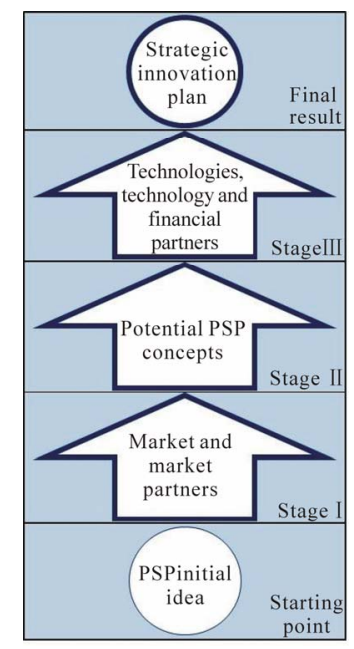

Figure 1. The stages of strategic innovation planning.

Once markets and potential MPs are identified, they must be prioritized. Some suggested prioritization criteria to do this are: market size, growth expectations, alignment with strategies of organization and expectations of market partnerships [17,22,34]. However, other criteria may be added according to the needs of the organization.

A list containing the priority markets and their corresponding MPs is submitted to a decision group, which may be composed by a general coordinator, backed by partners, the top tier of the organization, consultants and specialists, who will decide whether to approve the prioritization. If it is approved, the second follows, otherwise the process goes back and the market prioritization criteria are reassessed.

The stage II proposes the identification of potential PSP and the assessing the priorities to be developed. The objective of this stage is to identify and prioritize concepts of possible PSP based on the market prioritized in the stage I. They are just concepts because so far there is no detailed description of their specifications, but only a preliminary description.

The stage II begins with the thorough study of the priority market and its possible segments. The purpose of this study is to identify different groups of potential consumers who can contribute to the idealization of potential PSP concepts. Market segments may be distinguished based on diverse criteria, like geographical localization, extension, demography and economy among others.

A preliminary performance dimensions of the potential PSP these possibilities are also identified. It consists of the preliminary identification of attributes related to these PSP that have or may have some importance for the consumers or business. Among several possible dimensions of PSP performance can be the consumption of natural resources, emissions, energy efficiency, price/ cost, and financial potential among others.

It is to prioritize the market segments. Furthermore, it also important to identify their level of compliance to performance dimensions, which refers to how the PSP meets the needs of the segment in terms of the performance dimensions identified. A list of priorities PSP for each of the identified segments is submitted to the approval at the end of this stage.

The stage III proposes the identification of priorities potential technologies to be developed which me make possible to develop the PSP prioritized in the previous stage. Additionally, this stage assists in the identification of possible technology (TPs) and financial (FPs) partners, who may be mobilized in the development of different technologies to be prioritized.

The necessary technologies are defined through the identification of this PSP features and functionalities that would only be possible with the development of specific solutions, such as knowledge, machine or a set of specific skills and expertise.

The identified technologies are prioritized in order to make a distinction between the technology related to the organization's core business and other supplementary technologies. To this end, factors such as the technology alignment with the organization's strategy, the novelty degree of the technology, the possibility of establishing technological partnerships, among others, should be taken into consideration.

A list of priority technologies is performed to identify and prioritize possible FPs for these technologies, who can finance the technologies projects or just provide secondary resources to maintain structures or activities essential to the development of technologies. The FPs can be prioritized from some criteria like confidence, non-competing goals, capacity to pay, experience in collaboration, innovation expertise, familiarity in terms of reputation and friendship, honesty, motivation and interest in the partnership and cultural compatibility.

A list of technologies, TPs and FPs is submitted to the approval at the end of this stage. The final results, in the end of this sequence of stages, presents a strategic innovation plan document, which contain the market to be tapped, PSP to be developed, core and supplementary technologies to be developed and the necessary resources and partners to be mobilized. This can be a guide to the detailed planning and management of partner relationship during the innovation process. This process model makes sense in the context of the innovation network with partners as described at the Figure 2.

The Figure 2 represents the innovation process components considering the partner adoption from a strategic innovation planning. There are two different contexts to analyze, the innovation network and the worldwide market. The organization will integrate a network which make possible to transform its core technology and another ones, developed through the technology develop- 


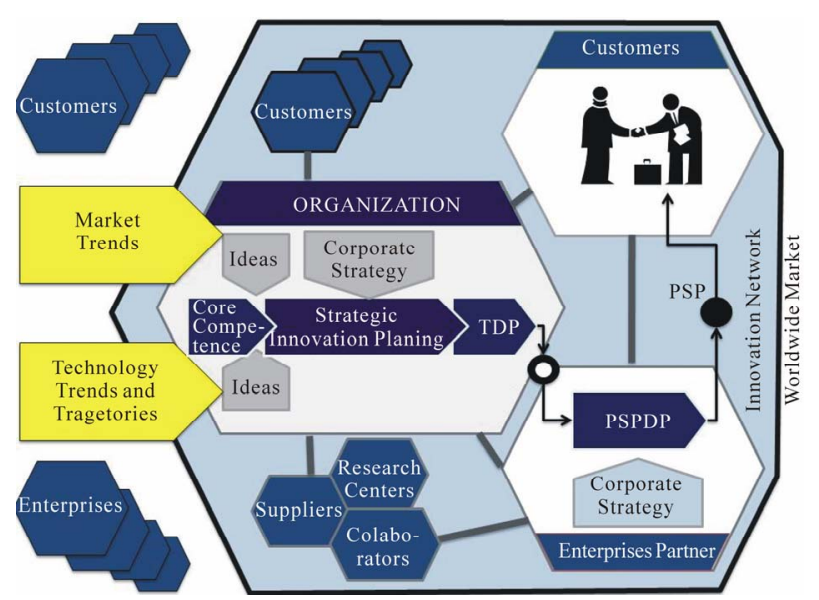

Figure 2. The strategic innovation planning at the innovation process.

ment process (PDT), in a commercial PSP, developed through a PSP development process (PSPDP). To this it is necessary to identify what is happened around the World, as market and technology trends, related to its technologies, the partners' interests and the costumers' needs.

\section{Conclusions}

This study presents the sequence of stages and the principal components of the strategic innovation planning considering the open innovation paradigm, e.g., the different classification of partner according to partnership interest and present a set of criteria for their selection and prioritization.

An advantage of this model is to show the possibilities to develop some technologies at a partner and the PSP at other ones simultaneously. This decrease the technology transfer time. The company partner, e.g., a manufacturing company, can conduct the product development incorporating the technology on development. So, the launched of this product in market can arrive faster, starting with those customers which helped during the innovation process-a kind of clients lead user. This makes the reduction of time of insertion of the product in the market.

The practical implications of this model to the strategic innovation planning is not just to organizations which develop technologies, but small and medium enterprises and another ones organization that wants plan their innovation using the open innovation paradigm. These organizations can use this model to choose the best way to be competitive on the market, realize partnership both in the technology development when in the PSP development. In addition, teachers can use this model in the classroom in the conceptualization of different elements of innovation, as market, PSP, technology and partnerships.
This study fills a literature gap on innovation planning considering the partnerships adoption and combines the organization needs to the open innovation paradigm. Future research should present results from the application of this strategic innovation planning model at different kind of organizations, technologies, products, services and process developed.

\section{Acknowledgements}

National Council for Scientific and Technological Development (CNPq), Institute for Product Development Management (IGDP), National Council for the Improvement of Higher Education (CAPES), Factory of Millennium Institute (IFM) and The State of Goias Research Foundation (FAPEG).

\section{REFERENCES}

[1] K. B. Clark and S. C. Wheelwright, "Managing New Product and Process Development: Text and Cases,” Free, New York, 1993.

[2] D. Clausing, "Total Quality Development: A Step-ByStep Guide to World-Class Concurrent Engineering,” American Society of Mechanical Engineers Press, New York, 1993.

[3] R. G. Cooper, "Managing Technology Development Projects,” Research Technology Management, Vol. 49, No. 6, 2006, pp. 23-31.

[4] C. M. Creveling, J. L. Slutsky and D. Antis, "Design for Six Sigma," In: Technology \& Product Development, Prentice Hall, New Jersey, 2003.

[5] A. Khurana and S. R. Rosenthal, "Towards Holistic Front Ends: In New Product Development,” Journal of Product Innovation Management, Vol. 15, No. 1, 1998, pp. 57-74. doi:10.1016/S0737-6782(97)00066-0

[6] S. Lee, S. Kang, Y. Park and Y. Park, “Technology Roadmapping for R \& D Planning: The Case of the Korean Parts and Materials Industry,” Technovation, Vol. 27, No. 8, 2007, pp. 433-445.

doi:10.1016/j.technovation.2007.02.011

[7] R. E. Albright and T. A. Kappel, “Technology Roadmapping: Roadmapping the Corporation," Research-Technology Management, Vol. 46, No. 2, 2003, pp. 31-41.

[8] M. Caetano and D. C. Amaral, "Roadmapping for Technology Push and Partnership: A Contribution for Open Innovation Environments,” Technovation, Vol. 31, No. 7, 2011, pp. 320-335. doi:10.1016/j.technovation.2011.01.005

[9] T. Daim and T. Oliver, "Implementing Technology Roadmap Process in the Energy Services Sector: A Case Study of a Government Agency,” Technological Forecasting and Social Change, Vol. 75, No. 5, 2008, pp. 687-720. doi:10.1016/j.techfore.2007.04.006

[10] C. J. P. Farrukh, R. Phaal and D. R. Probert, “Technology Roadmapping: Linking Technology Resources into Business Planning,” International Journal of Technology Ma- 
nagement, Vol. 26, No. 1, 2003, pp. 2-19. doi:10.1504/IJTM.2003.003140

[11] N. Gerdsri, R. S. Vatananan and S. Dansamasatid, "Dealing with the Dynamics of Technology Roadmapping Implementation: A Case Study,” Technological Forecasting \& Social Change, Vol. 76, No. 1, 2009, pp. 50-60. doi:10.1016/j.techfore.2008.03.013

[12] C. Holmes and M. Ferrill, "The Application of Operation and Technology Roadmapping to Aid Singaporean SMES Identifies and Selects Emerging Technologies," Technological Forecasting \& Social Change, Vol. 72, No. 3, 2005, pp. 349-357. doi:10.1016/j.techfore.2004.08.010

[13] R. N. Kostoff and R. R. Schaller, "Science and Technology Roadmaps,” IEEE Transactions on Engineering Management, Vol. 48, No. 2, 2001, pp. 32-143.

[14] M. G. Oliveira and H. Rozenfeld, “Integrating Technology Roadmapping and Portfolio Management at the FrontEnd of New Product Development,” Technological Forecasting \& Social Change, Vol. 77, No. 8, 2010, pp. 13391354. doi:10.1016/j.techfore.2010.07.015

[15] R. Phaal, C. J. P. Farrukh and D. R. Probert, "T-Plan: Fast Start to Technology Roadmapping,” Institute of Manufacturing, Cambridge University, Cambridge, 2001.

[16] R. Wells, R. Phaal, C. J. P. Farrukh and D. Probert, "Technology Roadmapping for a Service Organization," Research-Technology Management, Vol. 47, No. 2, 2004, pp. 46-51.

[17] H. W. Chesbrough, "Open Innovation: The New Imperative for Creating and Profiting from Technology," Harvard Business School Press, Boston, 2006.

[18] U. Lichtenthaler, “Technology Exploitation in the Context of Open Innovation: Finding the Right 'Job' for Your Technology,” Technovation, Vol. 30, No. 7-8, 2010, pp. 429-435. doi:10.1016/j.technovation.2010.04.001

[19] E. K. R. E. Huizingh, "Open Innovation: State of the Art and Future Perspectives,” Technovation, Vol. 31, No. 1, 2011, pp. 2-9. doi:10.1016/j.technovation.2010.10.002

[20] M. K. Badawy, "Is Open Innovation a Field Of Study or a Communication Barrier to Theory Development? A Perspective,” Technovation, Vol. 31, No. 1, 2011, pp. 65-67. doi:10.1016/j.technovation.2010.09.006

[21] G. M. Scott, "Strategic Planning for High-Tech Product Development," Technology Analysis and Strategic Management, Vol. 13, No. 3, 2001, pp. 343-364. doi:10.1080/09537320120088174

[22] G. M. Scott, "Still not Solved: The Persistent Problem of IT Strategic Planning," Communications of the Association for Information Systems, Vol. 16, No. 1, 2005, p. 904.

[23] A. P. Schulz, D. P. Clausing, E. Fricke and H. Nigel, “Development and Integration of Winning Technologies as Key to Competitive Advantage,” Systems Engineering,
Vol. 3, No. 4, 2000, pp. 180-211. doi:10.1002/1520-6858(2000)3:4<180::AID-SYS2>3.0.C $\underline{\mathrm{O} ; 2-\mathrm{H}}$

[24] D. E. Whitney, “Assemble a Technology Development Toolkit,” Research Technology Management, Vol. 50, No. 5, 2007, pp. 52-58.

[25] C. Kim, H. Kim, S. H. Han, C. Kim, M. K. Kim and S. H. Park, "Developing a Technology Roadmap for Construction R \& D through Interdisciplinary Research Efforts," Automation in Construction, Vol. 18, No. 3, 2009, pp. 330-337. doi:10.1016/j.autcon.2008.09.008

[26] J. Lee, C. Lee and T. Kim, “A Practical Approach for Beginning the Process of Technology Roadmapping," International Journal of Technology Management, Vol. 47, No. 4, 2009, pp. 306-321. doi:10.1504/IJTM.2009.024432

[27] S. Lee, B. Yoon, C. Lee and J. Park, "Business Planning Based on Technological Capabilities: Patent Analysis for Technology-Driven Roadmapping,” Technological Forecasting \& Social Change, Vol. 76, No. 6, 2009, pp. 769786. doi:10.1016/j.techfore.2009.01.003

[28] U. Lichtenthaler, "Integrated Roadmaps for Open Innovation,” Research Technology Management, Vol. 51, No. 3, 2008, pp. 45-49. doi:10.1287/mnsc.1060.0641

[29] V. L. Mitchell and B. R. Nault, "Cooperative Planning, Uncertainty, and Managerial Control in Concurrent Design,” Management Science, Vol. 53, No. 3, 2007, pp. 375389.

[30] R. Mcadam, T. O’Hare and S. Moffett, "Collaborative Knowledge Sharing in Composite New Product Development: An Aerospace Study,” Technovation, Vol. 28, No. 5, 2008, pp. 245-256. doi:10.1016/j.technovation.2007.07.003

[31] P. Brereton, B. A. Kitchenham, D. Budgen, M. Turner and M. Khalil, "Lessons from Applying the Systematic Literature Review Process within the Software Engineering Domain,” Journal of Systems and Software, Vol. 80, No. 4, 2007, pp. 571-583. doi:10.1016/j.jss.2006.07.009

[32] P. Coughlan and D. Coghlan, “Action Research: Action Research for Operations Management,” International Journal of Operations \& Production Management, Vol. 22, No. 2, 2002, pp. 220-240. doi:10.1108/01443570210417515

[33] S. Ottosson, "Participation Action Research: A Key to Improved Knowledge of Management,” Technovation, Vol. 23, No. 2, 2003, pp. 87-94. doi:10.1016/S0166-4972(01)00097-9

[34] R. G. Cooper, "Perspective: The Stage-Gate ${ }^{\circledR}$ Idea-toLaunch Process-Update, What's New, and Nexgen System,” Journal of Product Innovation Management, Vol. 25, No. 3, 2008, pp. 213-232. doi:10.1111/j.1540-5885.2008.00296.x 